\title{
Hepatitis B-related hepatocellular carcinoma and stress: untangling the host immune response from clinical outcomes
}

\author{
Peter D Block ${ }^{1}$ (D), Brianna Shinn², Jin Hyang Kim³ \& Hie-Won Hann *,4 (D) \\ ${ }^{1}$ Department of Medicine, Thomas Jefferson University Hospital, Philadelphia, PA 19107, USA \\ ${ }^{2}$ Department of Gastroenterology \& Hepatology, Thomas Jefferson University Hospital, Philadelphia, PA 19107, USA \\ ${ }^{3}$ Bristol-Myers Squibb, 3401 Princeton Pike, Lawrenceville, NJ 08648, USA \\ ${ }^{4}$ Department of Gastroenterology \& Hepatology, Liver Disease Prevention Center, Philadelphia, PA 19107, USA \\ *Author for correspondence: Hie-Won.Hann@Jefferson.edu
}

Chronic hepatitis B virus (HBV) infection is a major public health challenge on the global scale. Affecting hundreds of millions worldwide, HBV is a leading risk factor for hepatocellular carcinoma (HCC). Clinical outcomes from chronic HBV infection are varied and appear to be influenced by a complex and dysregulated host immune response. In turn, much attention has been given to the immunologic response to HBV in an effort to identify host factors that lead to the development of HCC. However, the role of nonimmunologic host factors, such as chronic stress, in HBV-related HCC is poorly defined. Indeed, a growing appreciation for the effects of stress on chronic liver diseases raises the question of its role in chronic HBV infection. In this light, the present review will untangle the roles of key host factors in HBV-related HCC with an emphasis on chronic stress as a viable contributor. First discussed is the interplay of stress, inflammation and chronic liver disease. The host immune response's role as a driver of HBV-related HCC is then reviewed, allowing for a close exploration of the effects of stress on immune function in chronic hepatitis $B$ and as a potential risk factor for HBV-related HCC.

First draft submitted: 2 August 2020; Accepted for publication: 1 December 2020; Published online: 29 December 2020

Keywords: hepatitis B • hepatocellular carcinoma $\bullet$ immune response $\bullet$ stress

The hepatitis B virus (HBV) is a noncytopathic pathogen that takes residence in the liver. Perinatal infection with $\mathrm{HBV}$ is the predominate route of transmission in highly endemic regions of the world, including most of Asia and Africa [1]. Clinical outcomes from HBV exposure vary widely, ranging from a self-limited course to chronic infection with the heightened risk of cirrhosis and hepatocellular carcinoma (HCC) [2].

As an estimated 250-350 million individuals are chronically infected with the virus [3]. Clinical factors that determine outcomes with chronic HBV infection carry substantial public health importance. HBV is the most significant hepatocarcinogen [4], accounting for $25 \%$ of cases of liver cancer in developed countries and nearly $60 \%$ of cases in developing countries [5,6]. HCC can manifest in patients with chronic hepatitis B (CHB) with and without underlying cirrhosis $[7,8]$, where the 5 -year cumulative HCC risk in those with and without cirrhosis is respectively $9.7-15.5 \%$ and $0.6-2.4 \%$ [9]. While the incidence of HCC in those afflicted with CHB has decreased since the advent of antiviral therapy [10-13], the risk of HBV-related HCC is not eliminated [14-16].

The heterogeneity of clinical outcomes seen with $\mathrm{CHB}$ is the product of viral, host and environmental factors $[17,18]$. Prior research has identified multiple environmental and viral factors associated with worse outcomes with $\mathrm{CHB}$, including specific viral genotypes and viral gene mutations $[19,20]$, as well as concomitant exposures such as dietary aflatoxin [21]. The consequential contributions of host immune responses to HBV infection and subsequent development of HCC also remains an area of active investigation, as liver injury is considered an immune-driven process in $\mathrm{CHB}$ [22].

The effect of longstanding psychosocial stress on host immunity has gained increasing attention in the context of various chronic diseases, including cancer [23] and chronic liver diseases [24]. Indeed, commonly encountered in the 
Table 1. Types and tools to measure stress.

\begin{tabular}{|c|c|c|}
\hline \multicolumn{3}{|l|}{ A. Types of acute and chronic stress } \\
\hline & Acute & Chronic \\
\hline \multicolumn{3}{|l|}{ Psysiologic stressors on the liver } \\
\hline Alcohol & Yes & Yes \\
\hline Metabolic & No & Yes \\
\hline Viral & Yes & Yes \\
\hline \multicolumn{3}{|l|}{ Psychosocial stressors } \\
\hline Employment or personal finance challenges & Yes & Yes \\
\hline Impaired quality of life from medical condition & Yes & Yes \\
\hline Interpersonal conflicts & Yes & Yes \\
\hline Psychological disorders (anxiety and depression) & Yes & Yes \\
\hline \multicolumn{3}{|l|}{ B. Common tools to measure psychosocial stress } \\
\hline Instruments & Description & \\
\hline GHQ-12 & $\begin{array}{l}\text { Screening instrument to measure mental health disorders and stress } \\
\text { burden }\end{array}$ & \\
\hline LDQoL instrument & $\begin{array}{l}\text { Validated questionnaire to gauge quality of life in those with chronic } \\
\text { liver disease }\end{array}$ & \\
\hline PHQ-9 & Screens depressive symptoms via nine self-reported items & \\
\hline PSS & Measures self-reported stress levels & \\
\hline
\end{tabular}

clinical setting are patients who complain of stress-related symptoms related to their liver diseases. The potential importance of host factors, such as psychosocial stress, was recently exemplified in an observational case series of three HBV infected families that included identical twins, where chronically infected offspring manifest a range of clinical outcomes despite having identical HBV genotypes and similar host genomes [25].

Here, we review the host factors that contribute to HBV-related HCC, emphasizing the burgeoning intersection of chronic stress and chronic HBV infection. First discussed is the interplay of stress, inflammation and chronic liver disease. In turn, the host immune response's role as a driver of HBV-related HCC is reviewed, allowing for a close exploration of the effects of stress on immune function in $\mathrm{CHB}$ and as a potential risk factor for HBV-related HCC.

\section{Stress, inflammation \& chronic liver diseases}

Stress describes a state of behavioral, physiological and psychological responses to environmental demands that exceed a person's natural regulatory capabilities (Table $1 \mathrm{~A} \& \mathrm{~B}$ ). Acute stress responses are generally considered physiologic, eliciting physiological changes that lead to tissue injuries. Conversely, chronic psychosocial stress, which includes adverse life experiences, history of childhood trauma and poor social support [26], can have pathological effects that culminate in chronic inflammation.

Physiological stress to the liver include alcohol, fat, toxic metabolites and replication of viral hepatitis that can acutely confer oxidative stress to hepatocytes [27]. Oxidative stress manifests by overproduction of free radicals, reactive oxygen species or reactive nitrogen species beyond the neutralizing capacity of hepatocytes [28]. Consequently, damaged mitochondria of hepatocytes trigger NF- $\mathrm{B}$-mediated inflammatory pathways, releasing inflammatory mediators (cytokines and chemokines) to recruit phagocytes (neutrophils and monocytes) and lymphocytes to remove offensive agents [28]. Although the inflammatory pathway is the body's first-line defense mechanism, the levels and/or duration of oxidative stress beyond the physiological condition can result in the overly ambitious release of reactive oxygen/nitrogen species and inflammatory mediators by recruited cells at the already injured site. In addition, cells that normally resolve aberrant inflammation, including Treg, alternatively activated (M2) macrophages and myeloid derived suppressor cells, become dysfunctional as inflammation persists (Figure 1) [29-32].

This amplification and perpetuation of inflammation is the common key driver of advanced liver diseases, including alcoholic liver disease, nonalcoholic fatty liver disease, liver fibrosis and liver cancer. Not surprisingly, anti-oxidant agents have become a focal point of therapeutic strategies to break the progressive oxidative stress 


\section{Stress}

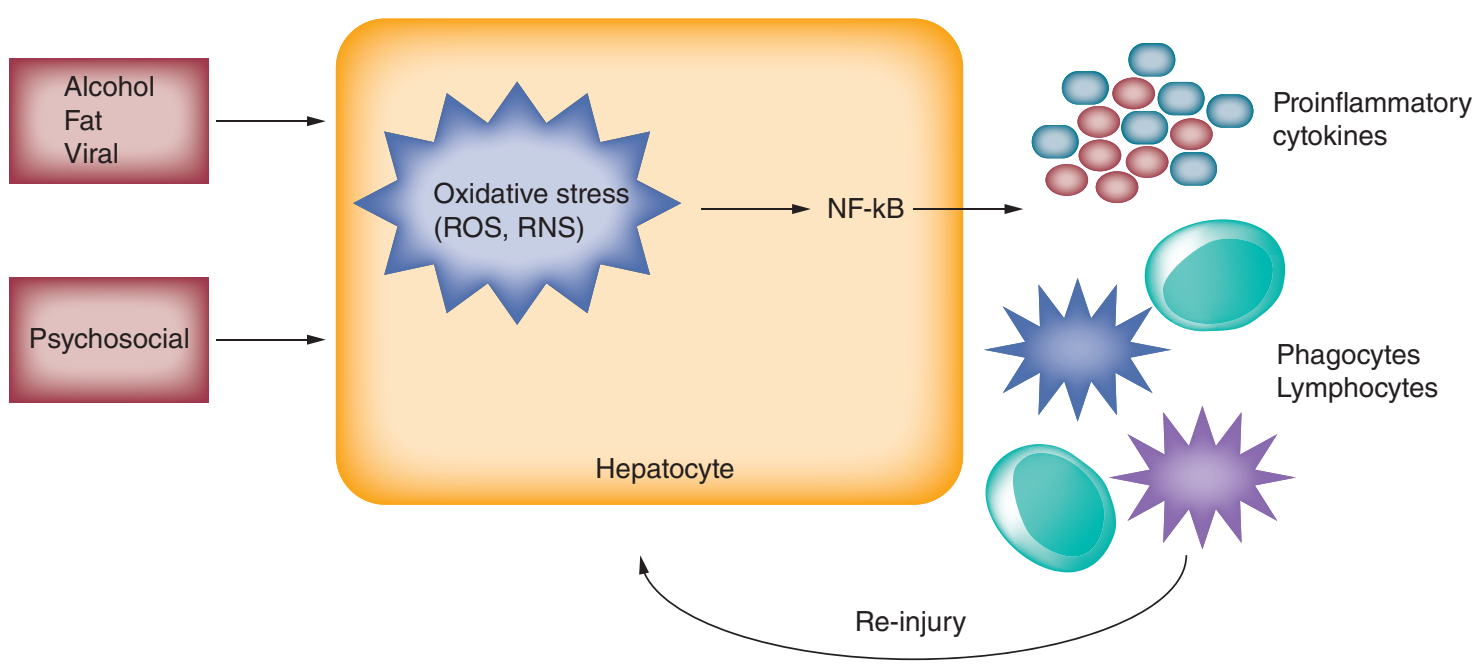

Figure 1. Hepatocyte injury-inflammation cycle from pathophysiological stressors. Alcohol, fat and viral infection are established hepatic stressors. Psychosocial stress may also lead to a similar pattern of hepatic injury. Pathophysiological stressors can trigger an oxidative stress reaction via overproduction of ROS and RNS. These oxidative species can precipitate NF- $\mathrm{BB}$-mediated inflammatory pathways, leading to release of pro-inflammatory cytokines and recruitment of phagocytic cells (neutrophils and monocytes) and lymphocytes. This inflammatory milieu within the liver can lead to continued hepatocyte injury.

RNS: Reactive nitrogen species; ROS: Reactive oxygen species.

and inflammation cycle [33]. Recent meta-analysis have shown that statins (HMG-CoA reductase inhibitors) are associated with both significantly reduced risk of cirrhosis development in HBV or hepatitis $\mathrm{C}$ virus patients, as well as decreased risk of cirrhotic complications [34,35]. These findings indicate that anti-inflammatory approaches may have important clinical value in mitigating advancement of liver disease. Similarly, Chinese medicinal herbs have gained attention due to their anti-oxidant and anti-inflammatory activities along with mild adverse effect profiles, which are reviewed in detail elsewhere [36].

Notably, growing appreciation for the ramifications of chronic psychological stress on poor health outcomes has brought to light the impact of stress on chronic liver disease. A recent meta-analysis by Russ et al. [37] demonstrated a dose-response correlation between psychological stress and mortality from advanced liver diseases among 166,631 individuals pooled from multiple health examination studies in the UK over 14 years. Although this study does not prove a cause-effect relationship 3 [38], it provides population-based evidence that links psychological stress to poor prognosis of liver diseases. Such a correlation was upheld even after controlling for other health behaviors, including alcohol consumption, diabetes mellitus, BMI and socioeconomic status.

Increasing clarity of the mechanisms underlying psychological stress-mediated liver damage has grown. Acute psychological stress can induce transient hepatic hypoxia and reperfusion injury, consequently leading to the release of damage associated molecular patterns (DAMPs), overactivation of natural killer (NK) cells, and polarization of Kupffer cells to a pro-inflammatory phenotype [39]. Furthermore, chronic psychological stress can lead to dysregulated effects of glucocorticoids and norepinephrine, which are respectively released by the hypothalamicpituitary-adrenal axis and sympathetic adrenomedullary system (Figure 2) [24,40-42]. Whereas glucocorticoids typically have anti-inflammatory properties under normal physiological circumstances, chronic stimulation of hypothalamic-pituitary-adrenal axis via psychological stress decreases its sensitivity to negative feedback loops leading to the amplification of pro-inflammatory cytokine milieu [43-47]. Norepinephrine can also promote secretion of inflammatory mediators through adrenergic receptor activation on innate immune cells [48]. Notably, animal models have shown that chronically elevated levels of corticosteroids and catecholamines promote production of hydroxyl radicals by hepatocytes [49], as well as production of Th2 pro-inflammatory cytokines (e.g., IL-6) by Kupffer cells and hepatocytes [39,48,50,51]. 


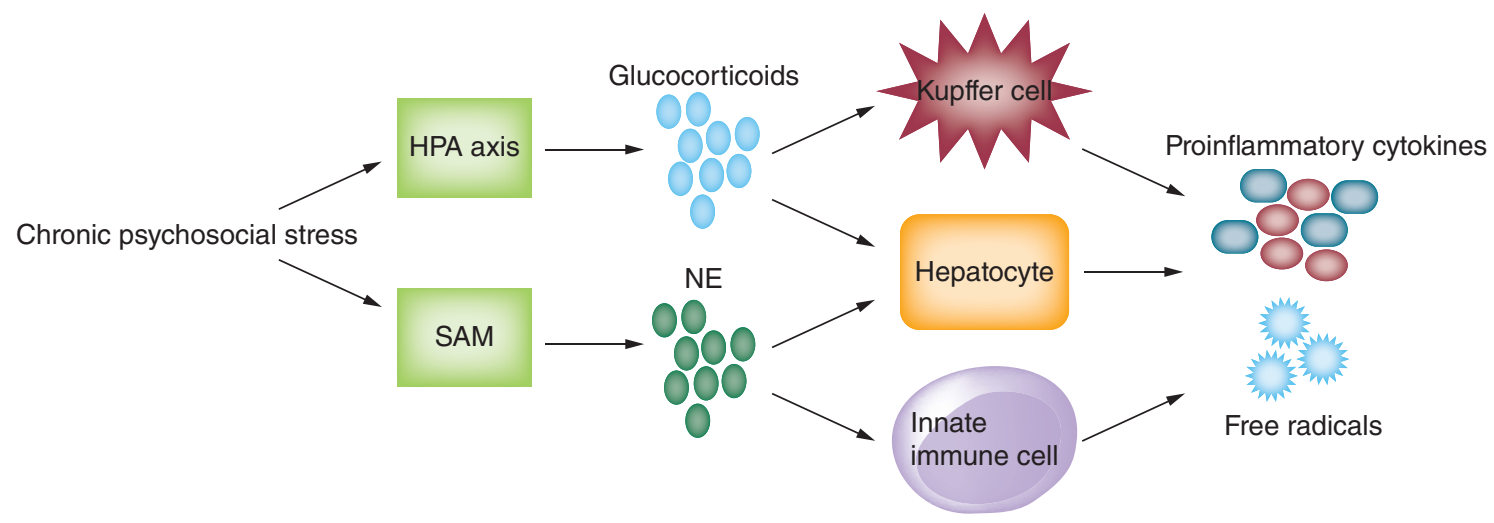

Figure 2. Proposed mechanisms of hepatic injury from chronic psychological stress. Chronic stress can promote release of NE via SAM system, activating innate immune cells possessing adrenergic receptors and leading to production of pro-inflammatory cytokines. Chronic stimulation of the HPA axis from psychosocial stress can decrease its sensitivity to negative feedback loops, leading amplification of pro-inflammatory cytokines by Kupffer cells. Both chronic glucocorticoid production and NE release can also stimulate hepatocytes to produce hydroxyl free radicals. HPA: Hypothalamic-pituitary-adrenal; NE: Norepinephrine; SAM: Sympathetic adrenomedullary system.

Moreover, strong inflammatory profiles due to psychological stress was reported by Pace et al. [52], who demonstrated that patients' severity of depression independently correlated with higher levels of pro-inflammatory markers (e.g., IL-6, NF- $\mathrm{KB}$ ) after undergoing induction of acute stress via the Trier Social Stress Test.

Collectively, the pathological repercussions of stress on chronic liver disease, whether physiological or psychological in nature, all converge on chronic inflammation initially triggered by mitochondrial dysfunction and DNA damage $[44,53,54]$.

\section{Host immune response as a driver of HBV-related HCC}

The prevailing pathology that underlies HBV-related HCC is chronic inflammation driven by persistent infection. HBV is a non-cytopathic virus [55] capable of deftly evading and impairing host immunological responses, leading to a dysregulated inflammatory state with resultant chronic liver injury.

Indeed, aberrancies within all branches of the immune system have been demonstrated throughout the lifecycle of $\mathrm{HBV}$ and are reviewed extensively elsewhere $[56,57]$. Of note, $\mathrm{HBV}$ replicates vigorously without triggering type I IFN pathway, effectively evading pathogen-sensing mechanisms of the innate immune system. This includes dysfunctional DNA and RNA sensing pathways, such as toll like receptor-9 [58,59] and RIG-I, that result in poor maturation of dendritic cells (DCs) [60,61]. Consequently, exhaustion of HBV-specific $T$ and B cells [62], characterized by expression of multiple inhibitory proteins such as arginase, Bim, CTLA-4, PD-1 and FoxP3 [61,63-65], further contribute to the chronicity of HBV infection. Their exhausted phenotypes result in ineffective clearance of virusinfected cells and amplification of a dysregulated inflammatory state, which promotes compensatory regenerative processes within damaged hepatocytes $[65,66]$.

In sum, persistent $\mathrm{HBV}$ infection coupled with ineffective immune responses establishes a chronic inflammatory state with compensatory hepatocyte proliferation. This vicious cycle leads to the indirect accumulation of host genomic alterations that can confer cell growth advantage, heightening the host's risk of liver cancer [67-69]. This has been illustrated by prior studies that have highlighted the importance of deregulated hepatocyte apoptosis [70,71], T-cell-mediated liver injury, and aberrant cytokine networks $[66,72,73]$ in the pathological process that leads to HBV-related HCC.

\section{Effects of stress on immune function in CHB}

Mounting evidence has linked psychosocial stress with CHB. Patients with CHB have significantly higher rates of depression [74], which has been consistently seen across different ethnicities, including Asian, European, and Middle Eastern populations [75,76]. Prior studies further indicate that most patients with CHB consider their associated symptoms to moderately impact daily life and view their diagnosis as a source of significant life stress [77-79]. Indeed, as we recently observed, hair cortisol levels are significantly repressed in patients with $\mathrm{CHB}$ compared with controls, further illustrating the chronicity of psychosocial stress within these patients [80]. 
Supporting these observations, an early study by Kunkel et al. found that higher scores on depression and psychosocial metric tests were associated with elevated transaminases in CHB patients [81], suggesting that these patients have higher background levels of hepatic injury. In regards to specific biological mechanisms for stressmediated immune suppression, definitive evidences remain lacking, although adrenergic receptors are shown to be present in all lymphocytes [82,83]. Stressors also induce the release of other pituitary hormones such as growth hormone, the brain peptides melatonin, beta-endorphin, and encephalin that can regulate the functions and distribution of leukocytes through activation of multiple different receptors [84]. A more recent study by He et al. showed a correlation between levels of psychosocial stress and a Th2-biased cytokine profile [85]. Using the 10point Perceived Stress Scale and State Trait Anxiety Inventory, He et al. demonstrated that increased psychosocial stress was associated with elevated levels of immunosuppressive cytokines (e.g., IL-10) and suppressed levels of immunoactivating cytokines (e.g., IFN- $\gamma$ ). Therefore, perturbation of nonspecific and HBV-specific immune cells from chronic psychological stress of CHB patients may lead to their quantitative and qualitative changes, though it may be subtle, and contribute to already impaired immunity and ongoing inflammation.

\section{Stress as a risk factor for HBV-related HCC}

Whether chronic stress in the setting of CHB contributes to either the onset or progression of HCC remains to be determined. To date, no study has examined the effects of psychosocial stress on HBV-related HCC. However, evidence supporting a link between chronic stress and malignancy has been found. Meta-analytic research showed that heightened levels of psychosocial stress is associated with an increased risk and poorer survival across an array of cancer types [23,86,87]. Indeed, a recent 5-year cohort study of 140,420 individuals from the Japan Public Health Center-based Prospective (JPHC) study found that chronically high levels of stress was linked to an overall $6 \%$ increase in cancer incidence, where the incidence of liver cancer was particularly elevated among those with persistently high levels of stress [88].

As described in [26], discordant clinical outcomes of identical twins infected with HBV at birth were observed, as one developed HCC at the age of 51 years and the other remained a healthy carrier. Considering that the twins had identical viral genotypes and near-identical host genomes, the possible role of nongenetic risk factors, such as stress, in the development of HBV-related HCC is poignantly underlined.

Finally, decreased levels of depressive symptoms and feelings of social isolation are associated with improved mortality outcomes in cancer patients [89,90]. Similarly, a large prospective cohort study of the Swedish population found that individuals' stress resilience, defined as an adaptive response to adverse events, strongly correlated with the reduction of their future risk of liver cancer [91].

\section{Conclusion}

The public health burden of hepatitis B underlines the importance of discerning the mechanisms that contribute to the virus' heterogeneous clinical outcomes. Illumination of the constellation of risk factors that predispose chronically infected individuals to HCC remains an essential goal of HBV research. Indeed, significant progress has been made in defining the interplay between $\mathrm{HBV}$ and host immune responses. This body of research has shown that the oncogenic nature of HBV is largely a byproduct of the inflammatory environment it creates. The virus' capacity to evade, exhaust and provoke dysynchronous immune responses fosters a pernicious inflammatory state within the liver that is susceptible to malignant transformation. Nevertheless, there remains much to be uncovered regarding the mechanisms that impair HBV-specific immune responses, particularly intrahepatic immune responses in CHB [92]. Clarifying these mechanisms could guide potential immunomodulatory therapies in both $\mathrm{CHB}$ and $\mathrm{HBV}$-related HCC [93].

\section{Future perspective}

The impact of nonimmunological host factors on clinical outcomes with CHB remains largely unexplored terrain. As discussed here, this is particularly true regarding the implications of psychosocial stress in patients with CHB. While previous studies have shown psychosocial stress to be widely prevalent among patients with $\mathrm{CHB}$, few studies have studied the immunological or clinical impact of chronic stress in this patient population. As CHB and chronic stress can cause both immune dysfunction and inflammation within the liver, there are shared and feasibly synergistic pathological effects. Moreover, chronic stress has also been shown to heighten individual's risks of cancer, including liver cancer. Despite these similarities, there is a dearth of literature on the potential role of psychosocial stress in the development of HBV-related HCC. This paucity of data provides an opportunity 
for further exploration and the potential identification of key players of inflammation that could provide novel therapeutic approaches for CHB- and HBV-related HCC.

\section{Executive summary}

- Hepatitis B remains a leading risk factor for hepatocellular carcinoma (HCC) despite the advent of antiviral therapy.

- Clinical outcomes from chronic hepatitis B virus (HBV) infection vary and are influenced by a dysregulated host immune response. The underlying pathology of HBV-related HCC is similarly driven by persistent viral infection and an inappropriate inflammatory state.

- Chronic stress can amplify and perpetuate inflammation that has negative consequences in both chronic liver disease and gastrointestinal malignancies.

- Immune function in chronic hepatitis B is impaired by chronic stress. This raises a plausible relationship between chronic stress and HCC development in chronic HBV infection. However, few studies have examined the impact of chronic stress on the development of HBV-related HCC.

- The paucity of research investigating the interplay between HBV-related HCC development and chronic stress warrants investigation at the pathophysiological and clinical level.

\section{Author contributions}

HW Hann conceived the idea for the manuscript. All authors were involved in the writing, editing and drafting of the manuscript.

\section{Financial \& competing interests disclosure}

The authors have no relevant affiliations or financial involvement with any organization or entity with a financial interest in or financial conflict with the subject matter or materials discussed in the manuscript. This includes employment, consultancies, honoraria, stock ownership or options, expert testimony, grants or patents received or pending, or royalties.

No writing assistance was utilized in the production of this manuscript.

\section{Open access}

This work is licensed under the Attribution-NonCommercial-NoDerivatives 4.0 Unported License. To view a copy of this license, visit http://creativecommons.org/licenses/by-nc-nd/4.0/

\section{References}

Papers of special note have been highlighted as: $\bullet$ of interest; $\bullet \bullet$ of considerable interest

1. Trepo C, Chan HL, Lok A. Chronic hepatitis B virus infection. Lancet 384, 2053-2063 (2014).

2. McMahon BJ. The natural history of chronic hepatitis B virus infection. Hepatology 49(S5), S45-S55 (2009).

3. Schweitzer A, Horn J, Mikolajczyk RT, Krause G, Ott JJ. Estimations of worldwide prevalence of chronic hepatitis B virus infection: a systematic review of data published between 1965 and 2013. Lancet 386(10003), 1546-1555 (2015).

4. El-Serag HB, Rudolph KL. Hepatocellular carcinoma: epidemiology and molecular carcinogenesis. Gastroenterology 132(7), 2557-2576 (2007).

5. MacLachlan JH, Cowie BC. Hepatitis B virus epidemiology. Cold Spring Harb. Perspect. Med. 5(5), 1-24 (2015).

6. Parkin DM, Pisani P, Ferlay J. Global cancer statistics. CA Cancer J. Clin. 49(1), 33-64 (1999).

7. Beasley RP, Hwang L-Y, Lin C-C, Chien C-S. Hepatocellular carcinoma and hepatitis B virus: a prospective study of 22,707 men in Taiwan. Lancet 2(8256), 1129-1133 (1981).

8. Fattovich G, Bortolotti F, Donato F. Natural history of chronic hepatitis B: special emphasis on disease progression and prognostic factors. J. Hepatol. 48(2), 335-352 (2008).

9. Raffetti E, Fattovich G, Donato F. Incidence of hepatocellular carcinoma in untreated subjects with chronic hepatitis B: a systematic review and meta-analysis. Liver Int. 36(9), 1239-1251 (2016).

10. Liaw Y-F, Sung JJY, Chow WC et al. Lamivudine for patients with chronic hepatitis B and advanced liver disease. N. Engl. J. Med. 15(351), 1521-1531 (2004).

11. Eun JR, Lee HJ, Kim TN, Lee KS. Risk assessment for the development of hepatocellular carcinoma: according to on-treatment viral response during long-term lamivudine therapy in hepatitis B virus-related liver disease. J. Hepatol. 53(1), 118-125 (2010).

12. Hosaka T, Suzuki F, Kobayashi M et al. Long-term entecavir treatment reduces hepatocellular carcinoma incidence in patients with hepatitis B virus infection. Hepatology 58(1), 98-107 (2013). 
13. Kim WR, Loomba R, Berg T et al. Impact of long-term tenofovir disoproxil fumarate on incidence of hepatocellular carcinoma in patients with chronic hepatitis B. Cancer 121(20), 3631-3638 (2015).

14. Papatheodoridis GV, Lampertico P, Manolakopoulos S, Lok A. Incidence of hepatocellular carcinoma in chronic hepatitis B patients receiving nucleos(t)ide therapy: a systematic review. J. Hepatol. 53(2), 348-356 (2010).

15. Shinn BJ, Martin A, Coben RM et al. Persistent risk for new, subsequent new and recurrent hepatocellular carcinoma despite successful anti-hepatitis B virus therapy and tumor ablation: the need for hepatitis B virus cure. World J. Hepatol. 11(1), 65-73 (2019).

16. Dargan A, Wong SY, Coben R, Conn M, Dimarino AJ, Hann HW. Persistent risk for hepatocellular carcinoma after more than a decade of successful hepatitis B virus suppression. Minerva Gastroenterol. Dietol. 63(1), 74-76 (2017).

17. Liang TJ. Hepatitis B: the virus and disease. Hepatology 49(5), S13-S21 (2009).

18. Hoofnagle JH, Doo E, Liang TJ, Fleischer R, Lok ASF. Management of hepatitis B: summary of a clinical research workshop. Hepatology 45(4), 1056-1075 (2007).

19. Yu MW, Yeh SH, Chen PJ et al. Hepatitis B virus genotype and DNA level and hepatocellular carcinoma: a prospective study in men. J. Natl Cancer Inst. 97(4), 265-272 (2005).

20. Kao JH, Chen PJ, Lai MY, Chen DS. Basal core promoter mutations of hepatitis B virus increase the risk of hepatocellular carcinoma in hepatitis B carriers. Gastroenterology 124(2), 327-334 (2003).

21. Yim HJ, Lok ASF. Natural history of chronic hepatitis B virus infection: what we knew in 1981 and what we know in 2005. Hepatology 43(S1), S173-S181 (2006).

22. Dandri M, Locarnini S. New insight in the pathobiology of hepatitis B virus infection. Gut 61, i6-i17 (2012).

23. Chida Y, Hamer M, Wardle J, Steptoe A. Do stress-related psychosocial factors contribute to cancer incidence and survival? Nat. Clin. Pract. Oncol. 5(8), 466-475 (2008).

24. Vere CC, Teodor-Streba C, Streba LM, Ionescu AG, Sima F. Psychosocial stress and liver disease status. World J. Gastroenterol. 15(24), 2980-2986 (2009).

- Seminal review on the interplay between psychosocial stress and liver disease.

25. Block P, Shinn B, Roth C, Needleman L, Rosato E, Hann H-W. Vagaries of the host response in the development of hepatitis B-related hepatocellular carcinoma: a case series. Curr. Cancer Ther. Rev. Vol 3, 16 (2020).

- The variability of clinical outcomes encountered with chronic hepatitis $B$ is highlighted in this case series, emphasizing the potential role for the host immune response.

26. Chrousos GP, Gold PW. The concepts of stress and stress system disorders: overview of physical and behavioral homeostasis. JAMA 267(9), 1244-1252 (1992).

27. Cichoż-Lach H, Michalak A. Oxidative stress as a crucial factor in liver diseases. World J. Gastroenterol. 20(25), 8082-8091 (2014).

28. Li S, Hong M, Tan HY, Wang N, Feng Y. Insights into the role and interdependence of oxidative stress and inflammation in liver diseases. Oxid. Med. Cell. Longev. 2016, 1-21 (2016).

29. Ma X, Hua J, Mohamood AR, Hamad ARA, Ravi R, Li Z. A high-fat diet and regulatory T cells influence susceptibility to endotoxin-induced liver injury. Hepatology 46(5), 1519-1529 (2007).

30. Oo YH, Weston CJ, Lalor PF et al. Distinct roles for CCR4 and CXCR3 in the recruitment and positioning of regulatory $\mathrm{T}$ cells in the inflamed human liver. J. Immunol. 184(6), 2886-2898 (2010).

31. Resheq YJ, Li K-K, Ward ST et al. Contact-dependent depletion of hydrogen peroxide by catalase is a novel mechanism of myeloid-derived suppressor cell induction operating in human hepatic stellate cells. J. Immunol. 194(6), 2578-2586 (2015).

32. Lee J, French B, Morgan T, French SW. The liver is populated by a broad spectrum of markers for macrophages. In alcoholic hepatitis the macrophages are M1 and M2. Exp. Mol. Pathol. 96(1), 118-125 (2014).

33. Bonner MY, Arbiser JL. The antioxidant paradox: what are antioxidants and how should they be used in a therapeutic context for cancer. Future Med. Chem. 6(12), 1413-1422 (2014).

34. Wang Y, Xiong J, Niu M et al. Statins and the risk of cirrhosis in hepatitis B or C patients: a systematic review and dose-response meta-analysis of observational studies. Oncotarget 8(35), 59666-59676 (2017).

35. Wan S, Huang C, Zhu X. Systematic review with a meta-analysis: clinical effects of statins on the reduction of portal hypertension and variceal haemorrhage in cirrhotic patients. BMJ Open. 9(7), 1-20 (2019).

36. Lam P, Cheung F, Tan HY, Wang N, Yuen MF, Feng Y. Hepatoprotective effects of Chinese medicinal herbs: a focus on anti-inflammatory and anti-oxidative activities. Int. J. Mol. Sci. 17(4), 1-37 (2016).

37. Russ TC, Kivimäki M, Morling JR, Starr JM, Stamatakis E, Batty GD. Association between psychological distress and liver disease mortality: a meta-analysis of individual study participants. Gastroenterology 148(5), 958-966.e4 (2015).

-• Meta-analysis of data from over 160,000 individuals during a 14-year period of time, illustrating a significant association between general health questionnaire (GHQ-9) scores and liver disease mortality.

38. Bonkovsky HL. On stress and the liver: a chicken and egg conundrum. Gastroenterology 148(5), 894-897 (2015). 
39. Joung JY, Cho JH, Kim YH, Choi SH, Son CG. A literature review for the mechanisms of stress-induced liver injury. Brain Behav. 9(3), $1-8$ (2019).

40. Chrousos GP. The hypothalamic-pituitary-adrenal axis and immune-mediated inflammation. N. Engl. J. Med. 332(20), 1351-1363 (1995).

41. Kim YK, Maes M. The role of the cytokine network in psychological stress. Acta Neuropsychiatr. 15(3), 148-155 (2003).

42. Moynihan JA. Mechanisms of stress-induced modulation of immunity. Brain Behav. Immun. 17, S11-S16 (2003).

43. Mcewen BS, Gianaros PJ. Central role of the brain in stress and adaptation: links to socioeconomic status, health, and disease. Ann. $N Y$ Acad. Sci. 1186, 190-222 (2010).

44. Bortolato B, Hyphantis TN, Valpione $\mathrm{S}$ et al. The many biobehavioral pathways driving tumor progression. Cancer Treat. Rev. 52, 58-70 (2017).

45. Howren MB, Lamkin DM, Suls J. Associations of depression with c-reactive protein, IL-1, and IL-6: a meta-analysis. Psychosom. Med. 71(2), 171-186 (2009).

46. Dowlati Y, Herrmann N, Swardfager W et al. A meta-analysis of cytokines in major depression. Biol. Psychiatry 67(5), 446-457 (2010).

47. Liu Y, Ho RCM, Mak A. Interleukin (IL)-6, tumour necrosis factor alpha (TNF- $\alpha$ ) and soluble interleukin-2 receptors (sIL-2R) are elevated in patients with major depressive disorder: a meta-analysis and meta-regression. J. Affect. Disord. 139(3), 230-239 (2012).

48. Scanzano A, Cosentino M. Adrenergic regulation of innate immunity: a review. Front. Pharmacol. Vol 171, 6 (2015).

49. Yang LJ, Liu X, Liu DX et al. Effects of different adrenergic blockades on the stress resistance of Wistar rats. Neurosci. Lett. 511(2), 95-100 (2012).

50. Zhou M, Yang S, Koo DJ, Ornan DA, Chaudry IH, Wang P. The role of Kupffer cell $\alpha 2$-adrenoceptors in norepinephrine-induced TNF- $\alpha$ production. Biochim. Biophys. Acta, Mol. Basis Dis. 1537(1), 49-57 (2001).

51. Jung BD, Kimura E, Kitamura $\mathrm{H}$ et al. Norepinephrine stimulates interleukin-6 mRNA expression in primary cultured rat hepatocytes. J. Biochem. 127(2), 205-210 (2000).

52. Pace TWW, Mletzko TC, Alagbe $\mathrm{O}$ et al. Increased stress-induced inflammatory responses in male patients with major depression and increased early life stress. Am. J. Psychiatry 163(9), 1630-1633 (2006).

53. Gong Y, Chai Y, Ding JH, Sun XL, Hu G. Chronic mild stress damages mitochondrial ultrastructure and function in mouse brain. Neurosci. Lett. 488(1), 76-80 (2011).

54. Moylan S, Maes M, Wray NR, Berk M. The neuroprogressive nature of major depressive disorder: pathways to disease evolution and resistance, and therapeutic implications. Mol. Psychiatry. 18(5), 595-606 (2013).

55. Ganem D, Prince AM. Hepatitis B virus infection-natural history and clinical consequences. N. Engl. J. Med. 350, 1118-1129 (2004).

56. Bauer T, Sprinzl M, Protzer U. Immune control of hepatitis B virus. Dig. Dis. 29(4), 423-433 (2011).

57. Zhang Z, Zhang JY, Wang LF, Wang FS. Immunopathogenesis and prognostic immune markers of chronic hepatitis B virus infection. J. Gastroenterol. Hepatol. 27(2), 223-230 (2012).

58. Momeni M, Zainodini N, Bidaki R et al. Decreased expression of toll like receptor signaling molecules in chronic HBV infected patients. Hum. Immunol. 75(1), 15-19 (2014).

59. Ratnam DT, Sievert W, Visvanathan K. Natural killer cells display impaired responses to toll like receptor 9 that support viral persistence in chronic hepatitis B. Cell. Immunol. 279(1), 109-115 (2012).

60. van der Molen RG, Sprengers D, Binda RS et al. Functional impairment of myeloid and plasmacytoid dendritic cells of patients with chronic hepatitis B. Hepatology 40(3), 738-746 (2004).

61. Li T-Y, Yang Y, Zhou G, Tu Z-K. Immune suppression in chronic hepatitis B infection associated liver disease: a review. World J. Gastroenterol. 25(27), 3527-3537 (2019).

62. Ye B, Liu X, Li X, Kong H, Tian L, Chen Y. T-cell exhaustion in chronic hepatitis B infection: current knowledge and clinical significance. Cell Death Dis. 6, e1694 (2015).

63. Lopes AR, Kellam P, Das A et al. Bim-mediated deletion of antigen-specific CD8+ T cells in patients unable to control HBV infection. J. Clin. Invest. 118(5), 1835-1845 (2008).

64. $\mathrm{Xu} \mathrm{D}, \mathrm{Fu}$ J, Jin $\mathrm{L}$ et al. Circulating and liver resident $\mathrm{CD} 4+\mathrm{CD} 25+$ regulatory t cells actively influence the antiviral immune response and disease progression in patients with hepatitis B. J. Immunol. 177(1), 739-747 (2006).

65. Das A, Hoare M, Davies N et al. Functional skewing of the global CD8 T cell population in chronic hepatitis B virus infection. J. Exp. Med. 205(9), 2111-2124 (2008).

66. Ringelhan M, O'Connor T, Protzer U, Heikenwalder M. The direct and indirect roles of HBV in liver cancer: prospective markers for HCC screening and potential therapeutic targets. J. Pathol. 235(2), 355-367 (2015).

67. An P, Xu J, Yu Y, Winkler CA. Host and viral genetic variation in HBV-related hepatocellular carcinoma. Front. Genet. 9(261), 1-15 (2018).

- Comprehensive article summarizing genetic factors influencing hepatitis B virus-associated hepatocellular carcinoma. 
68. Block TM, Guo H, Guo JT. Molecular virology of hepatitis B virus for clinicians. Clin. Liver Dis. 11(4), 685-706 (2007).

69. Vandeven N, Nghiem P. Pathogen-driven cancers and emerging immune therapeutic strategies. Cancer Immunol. Res. 2(1), 9-14 (2014).

70. Weber A, Boger R, Vick I et al. Hepatocyte-specific deletion of the antiapoptotic protein myeloid cell leukemia-1 triggers proliferation and hepatocarcinogenesis in mice. Hepatology 51(4), 1226-1236 (2010).

71. Xiao M, Chen W, Wang $\mathrm{C}$ et al. Senescence and cell death in chronic liver injury: roles and mechanisms underlying hepatocarcinogenesis. Oncotarget 9(9), 8772-8784 (2018).

72. Pikarsky E, Porat RM, Stein I et al. NF-kB functions as a tumour promoter in inflammation-associated cancer. Nature 431(7007), 461-466 (2004).

73. Luedde T, Schwabe RF. NF-кB in the liver: linking injury, fibrosis and hepatocellular carcinoma. Nat. Rev. Gastroenterol. Hepatol. 8(2), 108-118 (2011).

74. Huang X, Liu X, Yu Y. Depression and chronic liver diseases: are there shared underlying mechanisms? Front. Mol. Neurosci. 10(8), 1-36 (2017).

75. Altindag A, Cadirci D, Sirmatel F. Depression and health related quality of life in non-cirrhotic chronic hepatitis B patients and hepatitis B carriers. Neurosciences (Riyadh) 14(1), 56-59 (2009).

76. Hazaveh MM, Toosi TD, Toosi MN, Tavakoli A, Shahbazi F. Prevalence and severity of depression in chronic viral hepatitis in Iran. Gastroenterol. Rep. 3(3), 234-237 (2015).

77. Hann HW, Han SH, Block TM et al. Symptomatology and health attitudes of chronic hepatitis B patients in the USA. J. Viral Hepat. 15(1), 42-51 (2008).

78. Atesci FC, Cetin BC, Oguzhanoglu NK, Karadag F, Turgut H. Psychiatric disorders and functioning in hepatitis B virus carriers. Psychosomatics 46(2), 142-147 (2005).

79. Siew CO, Mak B, Myat OA, Li SC, Lim SG. Health-related quality of life in chronic hepatitis B patients. Hepatology 47(4), 1108-1117 (2008).

80. Hann HW, Meyer J, Park G, Block PD, Juon H-S. Hair cortisol and chronic stress exposure in chronic Hepatitis B. Clin. Invest. 9(4), 121-127 (2019).

81. Kunkel EJS, Sung Kim J, Hann HW et al. Depression in Korean immigrants with hepatitis B and related liver diseases. Psychosomatics 41(6), 472-480 (2002).

82. Anstead MI, Hunt TA, Carlson SL, Burki NK. Variability of peripheral blood lymphocyte beta-2-adrenergic receptor density in humans. Am. J. Respir. Crit. Care Med. 157(3 Pt I), 990-992 (1998).

83. Maisel AS, Fowler P, Rearden A, Motulsky HJ, Michel MC. A new method for isolation of human lymphocyte subsets reveals differential regulation of $\beta$-adrenergic receptors by terbutaline treatment. Clin. Pharmacol. Ther. 46(4), 429-439 (1989).

84. Fleshner M, Laudenslager ML. Psychoneuroimmunology: then and now. Behav. Cogn. Neurosci. Rev. 3(2), 114-130 (2004).

85. He YL, Gao H, Li XM, Zhao YR. Psychological stress exerts effects on pathogenesis of hepatitis B via type-1/type-2 cytokines shift toward type-2 cytokine response. PLoS ONE 9(8), e105530 (2014).

86. Green Mcdonald P, O'connell M, Lutgendorf SK. A decade of discovery, paradigm shifts, and methodological innovations. Brain Behav Immun. 30, S1-S9 (2013).

87. Kikuchi N, Nishiyama T, Sawada T et al. Perceived stress and colorectal cancer incidence: the Japan collaborative cohort study. Sci. Rep. Vol 7, 7 (2017).

88. Song H, Saito E, Sawada N et al. Perceived stress level and risk of cancer incidence in a Japanese population: the Japan Public Health Center (JPHC)-based prospective study. Sci. Rep. 7(1), 1-16 (2017).

-. Large prospective study demonstrating correlation between psychosocial stress and malignancy, where the incidence of liver cancer was particularly elevated among those with persistently high levels of stress.

89. Giese-Davis J, Collie K, Rancourt KMS, Neri E, Kraemer HC, Spiegel D. Decrease in depression symptoms is associated with longer survival in patients with metastatic breast cancer: a secondary analysis. J. Clin. Oncol. 29(4), 413-420 (2011).

90. Lutgendorf SK, De Geest K, Bender D et al. Social influences on clinical outcomes of patients with ovarian cancer. J. Clin. Oncol. 30(23), 2885-2890 (2012).

91. Kennedy B, Fang F, Valdimarsdóttir U, Udumyan R, Montgomery S, Fall K. Stress resilience and cancer risk: a nationwide cohort study. J. Epidemiol. Community Health 71(10), 947-953 (2017).

92. Bertoletti A, Ferrari C. Innate and adaptive immune responses in chronic hepatitis B virus infections: towards restoration of immune control of viral infection. Gut 61(12), 1754-1764 (2012).

93. Liang TJ, Block TM, McMahon BJ et al. Present and future therapies of hepatitis B: from discovery to cure. Hepatology 62(6), 1893-1908 (2015). 